\title{
Modeling Different Scenarios for Forecasting Human Resources Requirements in Taiwan's Recreational Farms
}

\author{
Teng Yuan $\mathrm{Hsiao}^{1}$ \& Yu Yao Hsu \\ ${ }^{1}$ Department of Leisure and Recreation Management, National Kaohsiung University of Hospitality and Tourism, \\ Taiwan \\ ${ }^{2}$ Graduate Institute of Travel and Tourism Management, National Kaohsiung University of Hospitality and Tourism, \\ Taiwan \\ Correspondence: Teng Yuan Hsiao, Associate Professor, Department of Leisure and Recreation Management, \\ National Kaohsiung University of Hospitality and Tourism, Taiwan. E-mail: tyhsiao@mail.nkuht.edu.tw
}

Received: September 22, 2014

Accepted: October 17, 2014

Online Published: November 16, 2014

doi:10.5430/ijba.v5n6p1

URL: http://dx.doi.org/10.5430/ijba.v5n6p1

\begin{abstract}
The demands of the rural recreational market have increased in recent years. Taiwan's rural area is also a popular travel destination for inbound tourists. Taiwan's recreational farms are the destinations that best represent the rural recreational experience. Taiwan's recreational agriculture association data show that Taiwan had 377 legal recreational farms in the year 2014. However, recreational farms face an area of management difficulty: how to achieve a fixed flow of human resources management. Hence, this study aimed to explore the optimal human resources in recreational farms by using system dynamics theory and modeling the financial, tourism and human resources subsystems as the decision making supports. Vensim 5.2 for Windows (Ventana Systems, Inc., 2012) was used as a research tool to test and verify two recreational farms in Taiwan as empirical cases. The results were used as the basis of the human resources requirements for recreational farm.
\end{abstract}

Keywords: recreational farm, human resources, system dynamics

\section{Introduction}

Since 2001, Taiwan has fully implemented a two-day weekend; moreover, personal incomes and disposable incomes for recreation travel are increasing. For these reasons, as well as additional background factors, short-distance recreation travel to nearby regions has increased yearly. Interest in tourism on the island of Taiwan and the number of tourism days have also increased from one-day city and suburb outings to two-day/one-night in-depth experiences that include travel and recreational activities across cities and counties. Accordingly, scenic areas, hotels, bed and breakfasts, the tourism industry, the transportation industry, and related industries have been expanding and developing, enhancing the diversity and operating efficiency of the existing tourism and recreational industry. Moreover, recreational farms have gradually become an important option for rural recreational experiences on two-day weekends and during holidays. To achieve the sustainable operation of recreational farms, in addition to understanding the farm's resource characteristics, operators must provide diverse recreational experiences that meet the recreational preferences of different tourists (He, Cai, \& Wu, 2010). However, the phenomenon of having crowds of tourists during holidays and few off-peak visitors remains widespread among recreational farms, leading to difficulty in the hiring and management of human resources; thus, there is a need for decision support systems that can help predict staffing needs during off-peak seasons. The extant literature on the sustainable operations management of recreational farms has only explored sustainability assessment factors and sustainable operation management indicators (Duan, 2010; Xu, 2006; Zeng, 2010), and few investigations have used operational indicators constructed to assess forecasting and decision support systems in follow-up studies. The objectives of this study are to explore each dimension of the relationship between human resources and operational processes within the operating systems of recreational farms and to produce a useful reference for decision-making regarding human resources operations and management. Vensim 5.2 for Windows (Ventana Systems, Inc., 2012) was used to establish a system dynamics model to describe and explain the human resources operations of recreational farms. Understanding the characteristics of the system dynamics model, simulating patterns of the demand for human resources, and proposing the final conclusions and suggestions are expected to help operators and managers more quickly understand the management decision-making processes related to the human resources of recreational farms. The Objectives of the study was summarized as: 
1)To establish a system dynamics model of human resources management that can forecast suitable models of human resources during both the peak season and the day-to-day operations of recreational farms.

2)To conduct in-depth interviews with two comprehensive and two experiential farms (Note 1), to use one comprehensive farm A and one experiential farm B as empirical case studies, and to analyze and discuss the simulation results.

\section{Literature Review}

According to the 2004 Comprehensive Survey of recreation Agriculture Farms in Taiwan, recreational agriculture in Taiwan has demonstrated an upward developmental trend and has attracted investment from a large number of farm operators. Thus, the recreational farm has become an agricultural transformation and development model (Taiwan Recreation Agriculture Association, 2004) in Taiwan; in particular, in rural areas, rural tourism has developed as an alternative to agriculture (Fleischer \& Tchetchik, 2005). Nilsson (2002) believed that to improve the value of farm products, agricultural tourism must be linked to the local social and cultural contexts at the farm level. In fact, agro-tourism provides visitors with direct contact with the rural world and reminds these visitors of natural and traditional farming practices (Contini, Scarpellini, \& Polidori, 2009). Duan (2006) stated that agricultural and rural resources can be divided into natural resources, landscape resources, industrial resources, cultural resources, and human resources; this classification provides the basis for the design of the experiential activities of recreational agriculture. Becattini and Omodei Zorini (2003) claimed that in agricultural tourism, farmers provide a range of services designed to satisfy various complex needs, including natural, social, and cultural demands. In summary, this study explored the resources of recreational farms, mainly in terms of human resources, with a particular focus on the relationship between these resources and the farm operational system.

Newman et al. (2005) believed that decision-making related to carrying capacity is extremely challenging when attempting to meet the diverse tastes and preferences of tourists. However, clear management objectives, such as relevant indicators and quality standards, can be developed to address carrying capacity. Shcherbina and Shembeleva (2010) have stated that in terms of the sustainable development of the tourism industry, the industry itself should provide contributions in accordance with sustainable standards and that information plays an important role in the sustainable development of the industry. The sustainable development of the tourism industry, in essence, is multifaceted, representing a broad concept and involving multiple criteria; moreover, destination management systems should also be included in the scope of the business. The goal of recreational farm operations management is to obtain operational profits by providing recreational services that satisfy visitors. In summary, the operations of recreation farms involve a wide scope. The operational indicators of recreation farms explored in this study were modified from Wang (2007) and Chen, Zhang, and Lin (2008). These indicators included the three constructs of finances, tourists, and human resource management, which are discussed below.

Forecasting the need for human resources refers to predicting scenarios of the demand for certain types of human resources in a country or an organization within a particular future period. A forecast can provide the basis for future human resources planning for a country and can be an important step in an organization's future human resource management $(\mathrm{Hu}, 1992)$. Most of the existing applied studies of demand for human resources in the tourism field have used the international tourist hotel industry and the general hotel industry as research topics (Bagri, Babu, \& Kukreti, 2010; Cai, 2006; Chang, Gong, \& Shum, 2011; Chen, 2004; Lu \& Hu, 1999; Taylor \& Finley, 2008; Yang, 2007), and few studies have estimated recreational farms' demands for human resources. In summary, this study explored the demand forecast for human resources through modeling with quantitative system dynamics methods and provided reference criteria to assist recreational farm owners with decision-making regarding future human resources demands.

System dynamics is a management system that was developed in the 1960s by Professor Jay W. Forrester of the Massachusetts Institute of Technology and based on system management concepts. System dynamics has been implemented as a computer simulation program that simulates the dynamics of complex issues. To examine interactive dynamic behaviors within a system, system dynamics integrates and modifies information theory, cybernetics and servo control systems, using causality and the concept of intelligent feedback to analyze the system structure and to explore the ways in which decision-making and the time delay in information transmission and decision-making processes impact system behavior. Through the growth or stability of the simulation system, the system provides decision-makers with optimal reference guidelines for solving the complex dynamics of social, economic, and management issues (Tu \& Zhang, 2010). The main components include stocks, flows, auxiliary variables, and relationships, and these components can be used to create a model using a flow chart drawn with computer software. At present, most studies that have applied system dynamics in the field of domestic and foreign tourism have explored the management models of tourism destinations and the dynamic trends of either a case study or the industry as a whole (Kuo, 2009; Jin, 2009; Kang, 2007; Li, Dong, \& Li, 2012; Rasmussen, Rasmussen, 
Reenberg, \& Proud, 2012; Sun, 2010; Wang, 2007); however, few studies have investigated recreational farms as research topics. In summary, system dynamics was used in this study as a method and tool for exploring the human resources and various operational aspects within the operating systems of recreational farms and as a support system to help decision-makers use effective technologies for testing and evaluating related policies.

\section{Methodology Design}

\subsection{Method}

This study used both qualitative and quantitative methods and included a literature search; in-depth interviews and system dynamics were used as the main research methods to explore and understand the research questions. In-depth interviews, a qualitative research method, were mainly conducted face-to-face. These interviews explored particular topics through in-depth discussions with the subjects. Patton (1990) noted that an in-depth interview is a qualitative research method that involves data collection, mainly through face-to-face verbal conversations that trigger direct quotations from individuals regarding their experiences, opinions, feelings, and knowledge (Patton, 1999).

Regarding the design of the interview outline, this study adopted semi-structured in-depth interviews based on the research background, research objective, relevant literature, and practical information. The examiner first interviewed recreational farm owners regarding their personal opinions on a given topic to develop a thorough understanding of the actual operational mode of each recreational farm. Next, based on the information obtained, this study constructed qualitative and quantitative system dynamics models. Finally, this study proposed a decision support system conducive to forecasting the medium- and long-term demand for human resources in the operation of recreational farms.

\subsection{Steps}

The system dynamics model was constructed of basic components that were concatenated into one system. These components included stocks, flows, and converters, and arrow lines were used as connectors to indicate the relationships between the components. "Stock" is used to describe accumulated and aggregate quantities of the entire dynamic system; "flow" refers to activity or liquidity; and "converter" is an ancillary description of a stock or flow. The principles and steps used to construct the system dynamics model are described briefly as follows: (a) Define the goals or objectives of the operational systems and subsystems of recreational farms. (b) Describe the current state of the operational systems and subsystems of recreational farms. (c) Establish the mathematical relationships among recreational farms' operational indicators and factors. (d) Begin the simulation of subsystem scenarios. (e) Explain the simulation results. (f) Implement modifications to the system. (g) Repeat the test and perform empirical validation of recreational farms.

\subsection{Objects and Data Collection}

To understand the dynamic behavior and the relationship between the tourists, finances, and human resource management of recreational farms in Taiwan, this study used semi-structured and unstructured approaches for extensive data collection. Triangulation was used for selected data to validate the authenticity of the respondents' conversations; alternatively, different respondents were interviewed to understand and interpret the same topic (Yin, 2003). Based on the current distribution of recreational farms in Taiwan, this study targeted a total of four farms in the counties and cities of Ilan County, Miaoli County, Nantou County and Kaohsiung City for interviews (these four farms were chosen because they were the ones in the selected cities and counties that were most willing to cooperate with the study). The interviews were conducted in July to September 2012, and the interviewees were mainly medium- and high-level operations managers. The interviews mainly explored the relationship between human resources management and various operational aspects of recreational farms. The interviews were all conducted on the farms (to avoid disturbing day-to-day operations); the average interview duration was 1 to 2 hours, with a total of six interviews per farm. In addition, the study also followed up with the farms' operations managers via several telephone calls and e-mails to ensure the accuracy of the interview contents and to obtain detailed internal operational data for the farms. Finally, one comprehensive farm and one experiential farm were used as case studies for validation.

To ensure that the model used in this study was comprehensive and complete, this study interviewed one expert in system dynamics modeling. A total of five interviews were conducted in September and October 2012 to help the modelers validate the model structure. The modelers also played the roles of researcher, interventionist and practitioner, providing assistance and/or discussing suitable human resources models for the farms.

\subsection{Limitations}

In this study, recreation farms were viewed as complex living organisms, with farm staff as the main driver and the utilization of the system space to generate economic profits as the main characteristic. Therefore, the 
system-situational simulation of a suitable model for the human resource demands of recreational farms was conducted without considering the possibility of emergencies. The primary objective of a specific system model is to simulate real-world operations; the existing technologies, however, cannot enable the system model to cover all operations-related factors in the real world. Thus, to simplify the relevant variables within the system and allow for convenient modeling and simulation, the boundaries and limitations of a system model must be defined. Therefore, this study established the following conditions and restrictions for the system model. (a)The system behavior must be continuous-This study assumed the continuous behavior of the recreational farm operational system model. Moreover, it was assumed that changes in system behavior were not subject to chance but instead reflected causal feedback relationships between behavior and influencing variables. (b)Defining the boundaries of the system space-In this study, personnel from two comprehensive farms and two experiential farms were interviewed, and one comprehensive farm and one experiential farm were used for verification. Subenterprises related to recreation farms (such as food processing plants or general stores) and farm production systems were not included in the scope of this study. The model used in this study primarily explored the human resources systems of recreational farms. (c)Defining the boundary of the system time-This study considered the human resources operational systems of recreational farms to be developed over the long term; thus, "month" was established as the system simulation time unit for the testing and simulation of the system status. The upcoming 10 to 15 years were set as the time boundary for the simulation and estimation of the future demand for human resources for the individual recreational farms.

\subsection{Components of System Dynamics}

The symbols of all components used in this study as shown in Table 1.

Table 1 . The symbols used in system dynamics

\begin{tabular}{ll}
\hline \multicolumn{1}{c}{ Type } & \multicolumn{1}{c}{ Meaning } \\
Stock / Level & $\begin{array}{l}\text { Items or objects in the real world that can be } \\
\text { transitively or cumulatively obtained over } \\
\text { time. }\end{array}$ \\
Auxiliary & $\begin{array}{l}\text { Points of control that determine the state of a } \\
\text { stock, indicating the rate of the inflow or } \\
\text { outflow of the stock, expressed as unit volume } \\
\text { / unit time. }\end{array}$ \\
\hline rate & $\begin{array}{l}\text { Expressed as an intermediary between stock } \\
\text { and flow, representing parameter values for } \\
\text { certain environments; allows for the input of } \\
\text { test functions or numeric values into the } \\
\text { system. }\end{array}$
\end{tabular}

Connector /

Wire

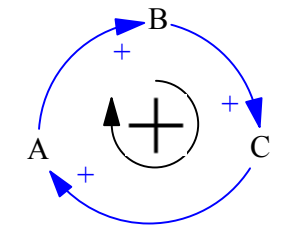

Links components such as stock, flow, and auxiliary variables; indicated by arrows.

Positive loop $\begin{aligned} & \text { Occurs when there is an even number of } \\ & \text { negative values in the loop, also known as a } \\ & \text { reinforcing loop. }\end{aligned}$

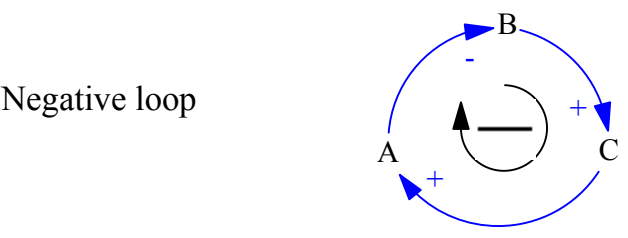

Source: Tu and Zhang (2010) 
In general, the validity of the tested model can be established by comparisons with the actual data, that is, by comparing the difference between the simulated model and the real world. If the results of the simulation are within an acceptable range, then they were accepted as valid. In this study, the validation testing of the study's structure and the modeling were performed at the same time. The relationships of the parameters within the system were verified through a series of interviews and related literature and survey reports. The integrity of the modeling was primarily verified using the expert validation method.

\section{Results and Discussion}

\subsection{The Demand for Human Resources on Recreational Farms: The Exploration of the Qualitative Model}

In this study, the construction of the qualitative model followed the following principles (Wang \& Lin, 2009): (a) The endogenous interpretation principle, which states that the dynamic of the growth in demand for human resources was derived from causality within the system. (b) There were many influencing variables in the model, but the endogenous interpretation was the main approach used in this study to explore the dynamics of the demand for human resources in the recreational farm industry; other variables were not included in this study's model. In addition, in this study, the causal feedback within the farm operational system was confirmed primarily by establishing hypotheses after a literature review and then verifying the existence and impact of the hypothesized feedback loop through in-depth interviews with farm owners. Moreover, the relationships were explained to farm owners after the model was completely developed, and the model was repeatedly modified to verify its accuracy (see Figure 1).

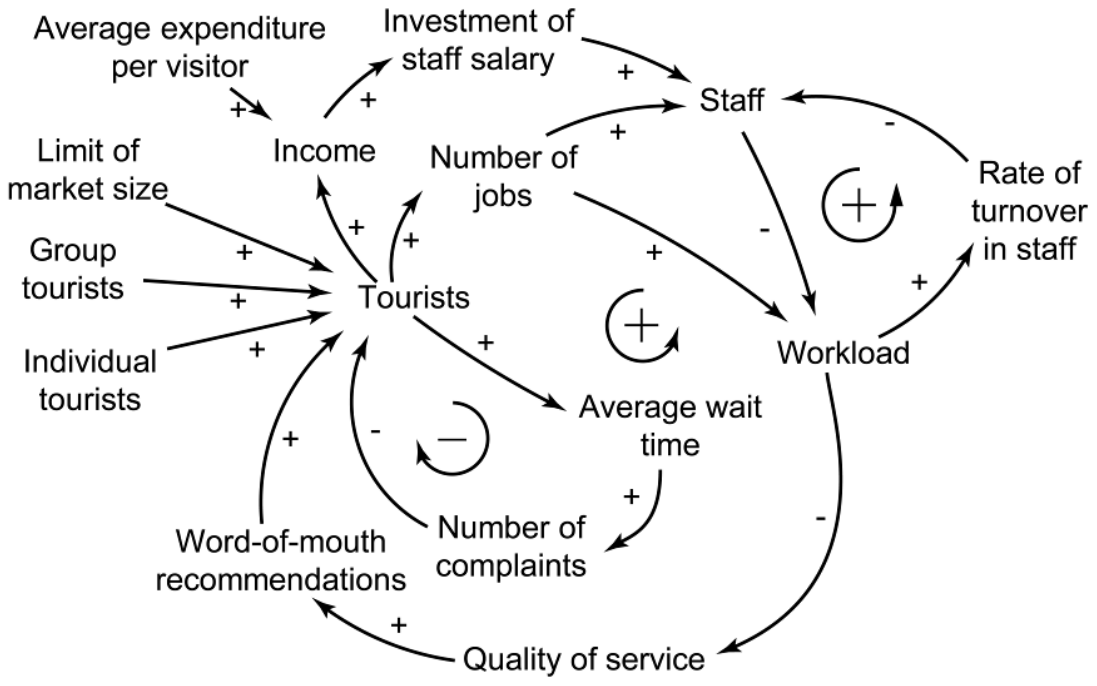

Figure 1. The exploration of the qualitative model

\subsection{The Demand for Human Resources on Recreational Farms: The Exploration of the Quantitative Model}

Within the scope of the operational system modeling of recreational farms, the employee subsystem was at the core and influenced other, more peripheral subsystems. In addition to the effects of the relationships between the different subsystems, there was also an interactive relationship of cause and effect within each subsystem, the details of which are shown in Figure 2. 


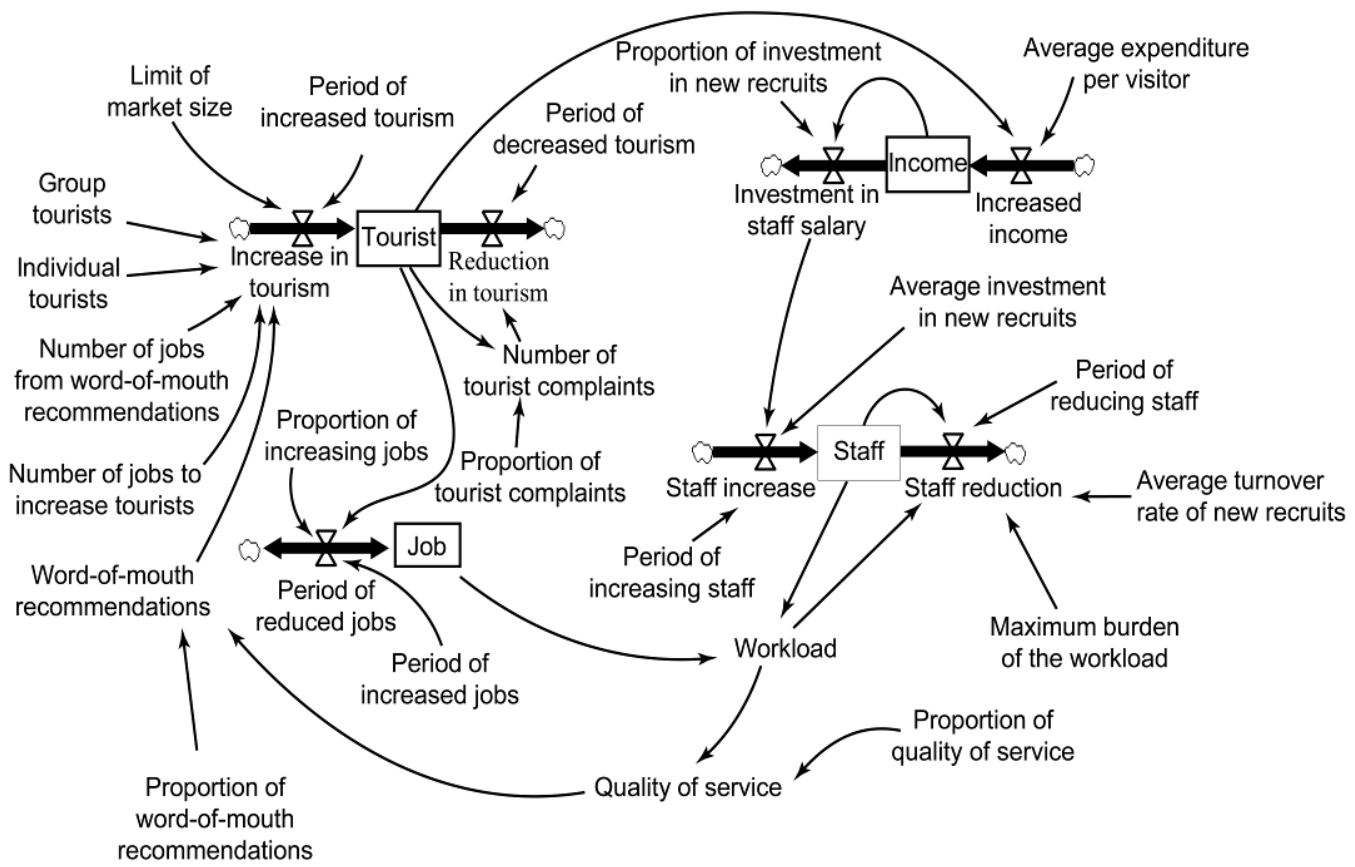

Figure 2. The exploration of the quantitative model

\subsection{Simulation Results-Cases Study of Farm A and Farm B}

The main objective of this study was to observe the impact of the demand for human resources under different operational strategies used by recreational farms and to simulate the operational structure of recreational farms using a dynamic simulation of the quantitative model. The next phase of the discussion will focus on the simulation of the normal operational behavior of case farm A and case farm B to observe the changes in their developmental trends and attempt to uncover topics that may be generated. Based on the situations defined by the relevant variables, this study analyzed the simulation of three different scenarios: weekdays, peak season, and off-season. This study expected to identify the key factors that affected the demand for human resources in the industry through simulation testing and to provide a reference for human resource management decisions for industry owners or government regulatory bodies.

\subsubsection{Case Farm: Comprehensive Farm A}

Number of weekday farm visitors-This study assumed that the number of farm visitors during peak season was 750 in groups and 1,750 individual visitors per month. The upper limit in the industry was 3,300 visitors.

Number of peak-season farm visitors-This study assumed that the number of farm visitors during peak seasons was 1,000 in groups and 2,500 individual visitors per month. The upper limit in the industry was 4,000 visitors.

Number of off-season farm visitors-This study assumed that the number of farm visitors during off-peak seasons was 500 in groups and 1,000 individual visitors per. The upper limit for the industry was 1,700 visitors.

The comparison with the simulation results of three operational scenarios is shown in Figure 3. 


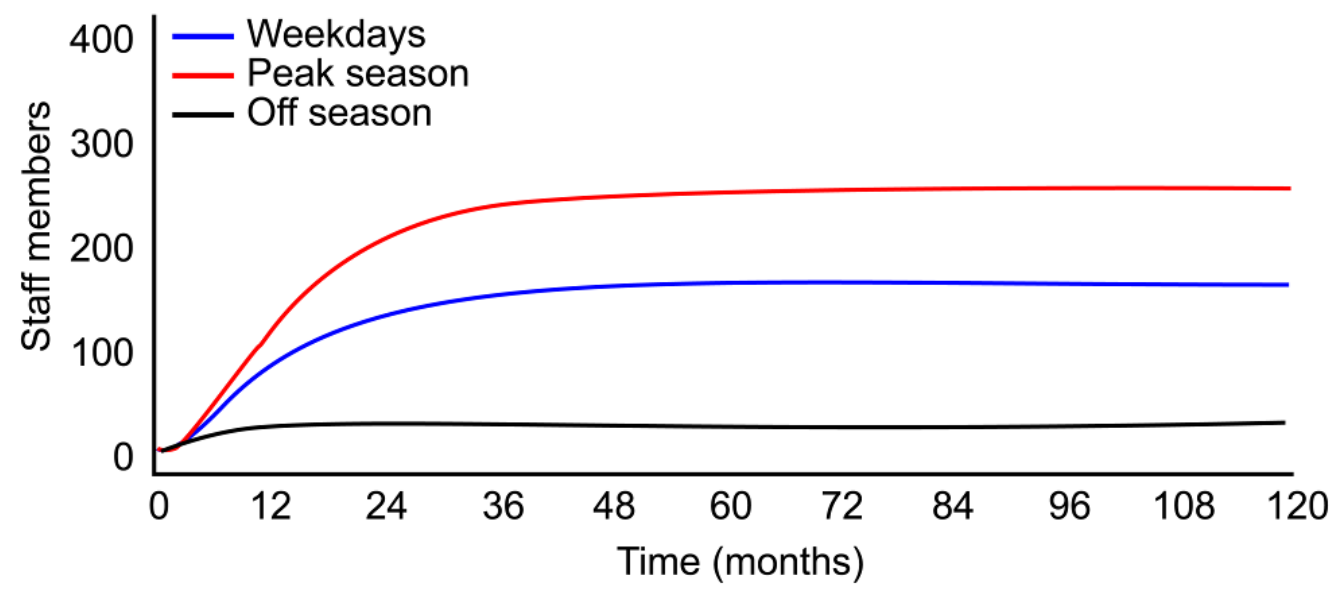

Figure 3. The comparison with the simulation results of three operational scenarios on farm A

\subsubsection{Case Farm: Experiential Farm B}

Number of weekday farm visitors-This study assumed that the number of farm visitors during peak seasons was 1,125 in groups and 125 individual visitors per month. The upper limit for the industry was 1,900 visitors.

Number of peak-season farm visitors-This study assumed that the number of farm visitors during peak seasons was 1,500 in groups and 600 individual visitors per month. The upper limit for the industry was 2,500 visitors.

Number of off-season farm visitors-This study assumed that the number of farm visitors during off-peak seasons was 80 in groups and 750 individual visitors per month. The upper limit for the industry was 1,400.

The comparison with the simulation results of three operational scenarios is shown in Figure 4.

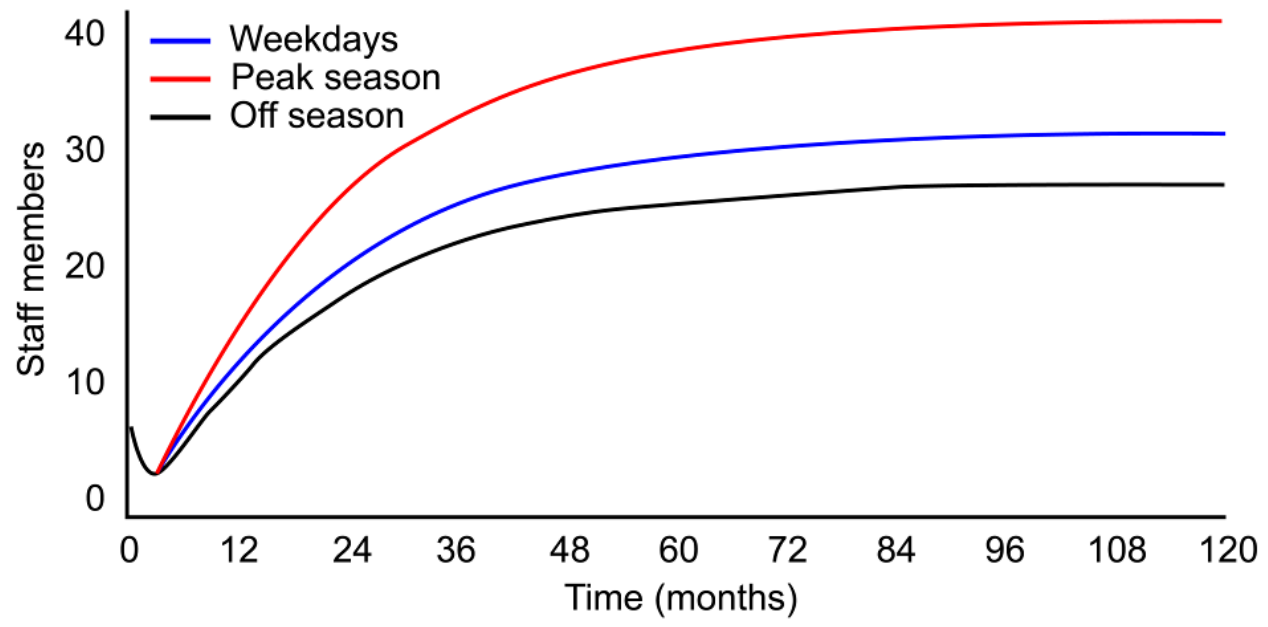

Figure 4. The comparison with the simulation results of three operational scenarios on farm B

\subsection{Discussion of Results}

The main findings of the simulation of different scenarios for comprehensive farm A and experiential farm B in this study are shown in Table 2.

Table 2. The results of the vensim simulation

\begin{tabular}{lll}
\hline \multicolumn{1}{c}{ Type } & \multicolumn{1}{c}{ Farm A (Unit: people) } & \multicolumn{1}{c}{ Farm B (Unit: people) } \\
\hline off-season & 1,500 tourists / 20-30 staff & 830 tourists / 5-10 staff \\
\hline weekday & 2,500 tourists / 30-150 staff & 1,250 tourists / 10-20 staff \\
\hline
\end{tabular}


In summary, this study found that the recreational farm owners' decisions regarding the number of employees were mainly subject to the influence of two variables: the monthly number of tourists and operating revenue. Overall, the turnover and employment rates of full-time employees of comprehensive and experiential farms were not high. Only in the case of new business entities or the development of new experiential activities would recreational farms recruit new full-time employees.In addition, at present, with respect to human resources demands, recreational farms often employ temporary or part-time staff to cope with the peak-season demand, in particular, the demand for staff that provide guided tours and catering is the highest. Therefore, the main findings of this paper are expected to help managers more quickly understand the factors that influence decisions about the human resource management of recreational farms.

\section{Conclusions}

This study used the Vensim software package to create a system dynamics model that could describe and explain the human resources management of recreational farms and could simulate models of demand for human resources under different policy scenarios, allowing managers to more quickly understand the decision-making processes related to the human resources management of recreational farms.

This study found that the inflow of employees to recreational farms depended mainly on the loop describing the number of tourists. Farm employees included both full-time employees (including reserve cadres and interns) and part-time employees. When the number of tourists increases, agricultural enterprises are driven to employ more part-time employees to maintain the farms' operations. The development of potential recreational resources would increase the farm owners' demand for professionals, which would in turn stimulate an increase in the number of farm employees. As the volume of farm business increases, the demand for the training that such employees require would also increase. It is recommended that farm owners implement certain education and training systems for new full-time and part-time employees to enhance these employees' professional skills and maintain the farms' service quality. The outflow of farm employees was primarily subject to the loop describing the turnover rate and was also affected by such variables as enterprise policies (including workload and employee benefits). With the rapid growth of a farm's business, if the owner still implements management practices in which employees perform several roles, service quality would be unstable and lead to negative word of mouth. Thus, this study recommends that farm owners implement specialization mechanisms based on the demand for business in the various departments of the farm.

It is not easy for certain farm owners to recruit new full-time employees; in particular, full-time employees are mostly local residents; thus, they are highly loyal to the farm, and the turnover rate among these employees is low. Moreover, many full-time employees are senior employees who earn good benefits, and it is difficult to recruit talent from outside the local area. Only the development of new business or service models (such as conference tourism, experiential activities, accommodations, or new processing plants) will require the farm owners to recruit permanent employees. Among such employees, the recruitment of full-time employees ("business staff") is the most difficult. At present, farm owners often resort to temporary (dispatched) employees or part-time employees to fill staffing gaps and to address the difference in the demand for employees between off-peak and peak seasons. To solve problems related to shortages of part-time employees, certain farm owners have also collaborated with non-governmental institutions to provide specific services, such as guided tours. Moreover, the operations of recreational farms are subject to the fluctuations of off-peak and peak seasons and external factors, such as natural disasters and government policies. This study found that the demand for human resources is positively correlated with the number of tourists. Therefore, the general situation of recreational farms in Taiwan is that the turnover ratios of part-time employees are higher than the turnover ratios among full-time employees.

In summary, this study found that the demand for human resources at recreational farms in Taiwan is growing year by year and that middle- and high-level administrators are the most difficult employees to recruit. Therefore, to fill the gap in middle-level management talents, recreational farm owners often resort to self-administered internal training, such as employing a veteran employee to train a novice or performing work in a rotational manner to allow employees to develop the professional skills required for different departments (such as dining, housekeeping, or guiding tours). It is recommended that farm executives participate in a variety of management courses administered by non-governmental and academic institutions.

This study has constructed a methodology to model the human resources requirement on comprehensive and experiential farms, providing suitable models of the demand for human resources that farm owners can reference and 
modify based on the size of their farms. Moreover, this study provides managers with a set of forecast tools for the scientific development of strategies.

This study's recommendations for future research are as follows: First, if researchers conduct follow-up research based on this study, such future investigations should use the general annual growth in the number of farms provided by relevant institutions and actual staffing statistics for the industry (including the number of comprehensive and experiential farms and the number of employees). In addition, further empirical research and discussion regarding the establishment of professional functions of farm employees is recommended to obtain a more complete understanding of the managerial implications of farm human resources.

\section{Acknowledgement}

This study was supported by Council of Agriculture, Executive Yuan, Taiwan, R.O.C.

\section{References}

Bagri, S. C., Babu, S., \& Kukreti, M. (2010). Human resource practices in hotels: A study from the tourist state of Uttrakhand, India. Journal of Human Resources in Hospitality \& Tourism, 9(3), 286-299. http://dx.doi.org/10.1080/15332841003749227

Becattini, G., \& Omodei Zorini, L. (2003). Rural identities and globalisation. In G. Becattini (Ed.), Industrial distructs: A new approach to industrial change (pp. 162-178). Northampton, MA: Edward Elgar.

Cai, Y. Q. (2006). A case analysis of human resources management in Taiwan's international tourist hotel industry. National Chengchi University Master's Thesis Taipei, Taiwan.

Chang, S., Gong, Y., \& Shum, C. (2011). Promoting innovation in hospitality companies through human resource management practices. International Journal of Hospitality Management, 30(4), 812-818. http://dx.doi.org/10.1016/j.jhm.2011.01.001

Chen, K. L., Zhang, S. C., \& Lin, F. Z. (2008). The establishment of recreational farms performance index - An instance from I-Lan County. Ilan University Journal of Bioresources, 4(2), 115-125.

Chen, Y. D. (2004). The application of systems thinking in the analysis of human resources strategies - A case study of the catering departments of Taiwanese international tourist hotels. National Taiwan Normal University Master's Thesis, Taipei, Taiwan.

Contini, C., Scarpellini, P., \& Polidori, R. (2009). Agri-tourism and rural development: The Low-Valdelsa case, Italy. Tourism Review, 64(4), 27-36. http://dx.doi.org/10.1108/16605370911004557

Duan, Z. L. (2006). The utilization of agricultural and rural resources to create recreational farms characteristics. Agriculture World, 271, 92-97.

Duan, Z. Y. (2010). A study of assessment factors for the sustainability of the physical environment of Taiwanese recreational farms. National Chung Hsing University Master's Thesis, Taichung, Taiwan.

Fleischer, A., \& Tchetchik, A. (2005). Does rural tourism benefit from agriculture? Tourism Management, 26(4), 493-501. http://dx.doi.org/10.1016/j.tourman.2003.10.003

He, B. C., Cai, X. Y., \& Wu, M. C. (2010). A study of the recreation experience satisfaction and customer retention of recreational farms: The case of the Matsuda Gang recreational farm. Agricultural Extension Anthology, 55(1), $127-146$.

Hu, Z. H. (1992). The first step to nurturing talent: The forecasting and methods of manpower demands. Quarterly Journal of Technological and Vocational Education, 8, 34-40.

Jin, X. (2009). An analysis of suburb tourism trend based on system dynamics method. Paper presented at the International Conference on Computer Engineering and Technology, Dalian, China.

Kang, J. H. (2007). Creating an economic model of a tourism-oriented community - A case study of the Taumi and Seshui districts. Jinan University Master's Thesis, Nantou, Taiwan.

Kuo, C. T. (2009). A system dynamics study exploring the dynamic decision-making in relationship marketing programs of a private distillery. University of Tainan Doctoral's Thesis, Tainan, Taiwan.

Li, F. J., Dong, S. C., \& Li, F. (2012). A system dynamics model for analyzing the eco-agriculture system with policy 
recommendations. Ecological Modelling, 227(24), 34-45. http://dx.doi.org/10.1016/j.ecolmodel.2011.12.005

Lu, P. X., \& Hu, M. L. (1999). The application of fuzzy multi-objectives to the staffing of international tourist hotels. Journal of Jin-Wen Institute of Technology, 9(3), 133-138.

Newman, P., Manning, R., Dennis, D., \& McKonly, W. (2005). Informing carrying capacity decision making in Yosemite National Park, USA using stated choice modeling. Journal of Park and Recreation Administration, 23(1), 75-89.

Nilsson, P. A. (2002). Staying on farms: An ideological background. Annals of Tourism Research, 29(1), 7-24.http://dx.doi.org/10.1016/S0160-7383(00)00081-5

Patton, M. Q. (1990). Qualitative evaluation and research methods. London, England: Sage.

Patton, M. Q. (1999). Qualitative research and evaluation methods. (Z. Y. Wu \& F. R. Li, Trans.) Taipei, Taiwan: Laureate Books. (Original work published 1990)

Rasmussen, L. V., Rasmussen, K., Reenberg, A., \& Proud, S. (2012). A system dynamics approach to land use changes in agro-pastoral systems on the desert margins of Sahel. Agricultural Systems, 107(1), 56-64. http://dx.doi.org/10.1016/j.agsy.2011.12.002

Shcherbina, O. A., \& Shembeleva, E. A. (2010). Modeling Tourism sustainable development. In T. Sobh \& K. Elleithy (Eds.), Innovations in computing sciences and software engineering (p.551-556). Dordrecht, Netherlands: Springer.

Sun, R. L. (2010). An exploration of the quality of subway passenger service using system dynamics. Chung Hua University Master's Thesis, Hsinchu, Taiwan.

Taiwan Recreational Agriculture Association. (2004). Final report of a comprehensive survey of recreation farms. Taipei, Taiwan: Council of Agriculture.

Taylor, M., \& Finley, D. (2008). Strategic human resource management in U.S. Luxury Resorts—A case study. Journal of Human Resources in Hospitality \& Tourism, 8(1), 82-95. http://dx.doi.org/10.1080/15332840802274460

Tu, Y. M., \& Zhang, L. Z. (2010). System dynamics: Theory and application. Taipei, Taiwan: John Wiley \& Sons.

Ventana Systems, Inc. (2012). System dynamics introduction. Retrived from http://www.vensim.com/

Wang, W. Y., \& Lin, J. W. (2009). Growth dynamics of Taiwan online game industry. Journal of Information Management, 16(2), 25-60.

Wang, X. J. (2007). The simulation and analysis of a sustainable system dynamic of theme parks $-A$ case study of Fancyworld. Chaoyang University of Technology Master's Thesis, Taichung, Taiwan.

$\mathrm{Xu}, \mathrm{J}$. Y. (2006). Indicators of sustainable management in a Taiwanese recreational agriculture area. Chaoyang University of Technology Master's Thesis, Taichung, Taiwan.

Yang, Y. Z. (2007). Key factors of human resources demands for the successful operation of international tourist hotels under the Capability Maturity Model Integration. Southern Taiwan University of Science and Technology Master's Thesis, Tainan, Taiwan.

Yin, R. K. (2003). Case study research: Design and methods. Thousand Oaks, CA: Sage.

Zeng, Y. R. (2010). The construction of indicators for the environmental design of a sustainable farm. Tunghai University Master's Thesis, Taichung, Taiwan. 


\section{Notes}

Note 1. Comprehensive and experiential farm are two kinds of Taiwan's legal recreational farm. The different of them are the scales of area and business items. The comprehensive farm should be set up to 5 hectare (ha) and have the facilities of activities, food\& beverage and accommodation. The experiential farm should be set up to 0.5 hectare (ha) and have the facilities of activities, food\& beverage.

Note 2. Vensim programming language is such as the following: recreational farm A on weekdays.

- $\quad$ Tourists $=$ INTEG (Increase in tourists - Reduce in tourists, 2500)

Units: people

- Group tourists $=750$

Units: people

- Individual tourists $=1750$

Units: people

- The number of jobs of word-of-mouth recommendations=12.6

Units: number

- The proportion of word-of-mouth recommendations $=0.3$

Units: undefined

- Word-of-mouth recommendations $=$ Quality of Service* The proportion of word-of-mouth recommendations Units: people / number

- $\quad$ The limit of the market size $=3300$

Units: people

- $\quad$ The number of jobs to increase tourists $=5$

Units: people

- Increase in tourists $=$ (The limit of the market size-( Group tourists + Individual tourists $)+$ Word-of-mouth recommendations* The number of jobs of word-of-mouth recommendations* The number of jobs to increase tourists) / The period of Increasing tourists

Units: people / month

- $\quad$ The period of reducing tourists $=1$

Units: month

- $\quad$ Reduce in tourists $=$ The number of complaints / The period of reducing tourists

Units: people / month

- The period of reducing tourists $=1$

Units: month

- $\quad$ The number of complaints $=$ Tourists $*$ The proportion of tourist complaints

Units: people

- $\quad$ The proportion of tourist complaints $=0.2$

Units: undefined

- $\quad$ Workload $=$ Staff $/$ Job

Units: people/number

Vensim programming language is such as the following: (B) recreational farm on weekdays.

- $\quad$ Tourists $=$ INTEG (Increase in tourists - Reduce in tourists, ,1250) 
Units: people

- Group tourists $=125$

Units: people

- $\quad$ Individual tourists $=1125$

Units: people

- $\quad$ The number of jobs of word-of-mouth recommendations $=$

Units: number

- $\quad$ The proportion of word-of-mouth recommendations $=0.1$

Units: undefined

- Word-of-mouth recommendations= Quality of Service * The proportion of word-of-mouth recommendations Units: people / number

- $\quad$ The limit of the market size $=1900$

Units: people

- $\quad$ The number of jobs to increase tourists $=3$

Units: people

- Increase in tourists $=($ The limit of the market size-( Group tourists + Individual tourists $)+$ Word-of-mouth recommendations* The number of jobs of word-of-mouth recommendations * The number of jobs to increase tourists) / The period of Increasing tourists

Units: people / month

- $\quad$ The period of reducing tourists $=1$

Units: month

- $\quad$ Reduce in tourists $=$ The number of complaints / The period of reducing tourists

Units: people / month

- $\quad$ The period of reducing tourists $=1$

Units: month

- $\quad$ The number of complaints $=$ Tourists $*$ The proportion of tourist complaints

Units: people

- $\quad$ The proportion of tourist complaints $=0.4$

Units: undefined

- $\quad$ Workload $=$ Staff $/$ Job

Units: people/number 